\title{
A new wave in creating customer satisfaction
}

Received (in revised form): 17th May, 2002

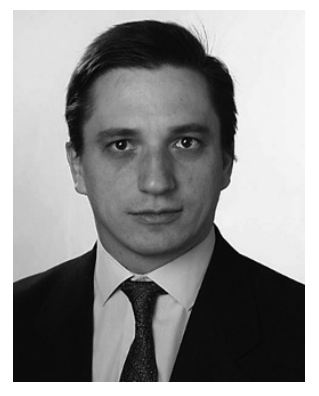

\section{Guy de Torcy}

joined Cincom in 2001 as Marketing Director for the iD Business Unit, and became Director of Marketing Europe for all Cincom Group activities in December of that year. He began his career in Spain at Group BNP-Paribas and was Marketing Manager at France Telecom for four years before joining Cincom. He holds an MBA from HEC (ISA) and is a postgraduate from the University of Dauphine.

Abstract The time has come for companies to put CRM theory into practice. Making your customers feel like they are important to you can be an expensive venture when you have thousands of them, but the right processes and support from personalised CRM systems can reduce costs significantly, shorten the lead times and limit the number of phone enquires from customers. To succeed in the 21 st century, companies need to equip themselves with content processing applications for the age of interactive customer communication.

\section{INTRODUCTION}

Competition has never been so fierce with competitors appearing from anywhere and everywhere. At the beginning of the 1990s, it was inconceivable that supermarkets would be launching financial service products. Being able to differentiate a company has been pronounced a major business advantage, but it can remain an elusive goal. Probably the most significant differentiator today is customer service and, for many companies, it has become critical.

The pressure on the customer service department is immense. Technology has created a significant rise in the volume and forms of communication. This, combined with the increase in customer expectations, is exacerbating the difficulty in delivering good customer service. It is, however, essential in the business world today.

\section{CUSTOMER COMMUNICATION}

Companies are now starting to put more effort into maintaining existing clients than gaining new ones. In market research conducted among 100 customer service managers ${ }^{1}$ from the financial services industry, it was discovered that 53 per cent of respondents communicate with their existing customers on a daily basis and only 40 per cent communicate daily with their prospects. Written correspondence is the most frequently used channel for this communication and is one of the widely used forms of customer contact, not to mention the only lasting form - 42 per cent of respondents use letters or e-mail and recognise it as the most important means of servicing customers.

Despite this, many companies feel that the relationship with their customers is not managed in the most efficient way. For example, 62 per cent think there is 
room for less duplication of effort. This is not surprising considering that 53 per cent of companies, sending more than 20,000 letters per month, do not have a system in place to manage it efficiently. The survey found that 62 per cent do not coordinate correspondence across departments; 12 per cent were not even able to say how many departments send out volume communication; while 52 per cent had at least three departments involved in volume communication.

The time to put the great customer relationship management (CRM) theory into practice is long overdue. Making customers feel that they are important to a company can be an expensive venture when there are thousands of them, but the right processes and support from personalised CRM systems can reduce costs significantly, shorten the lead times and limit the number of telephone enquiries from customers. Companies need to equip themselves with content processing applications for the age of interactive customer communication.

\section{PERSONAL CONTACT}

Novamétrie, a leading analyst group, found that 75 per cent of Europeans believe that contact with a real person cannot be replaced. ${ }^{2}$ What this actually means is far more important than what it actually says; it means treating the customer as an individual, dealing with him or her on a personal basis. It is this personal touch that counts, whether it is face to face, by telephone or by written communication. In some activities, like car sales, face-to-face contact is absolutely essential - in fact, Ipsos Novamearie has calculated that it is absolutely essential in 97 per cent of car sale situations. ${ }^{3}$

Novamétrie also found that 64 per cent associate new technologies with dehumanisation and lack of individual approach, leading to deterioration of the contact between the company and its customer. ${ }^{4}$ Understandably so, after all, how many people have been frustrated spending the first five minutes of a call being routed through 13 different options before being held in a queue to be answered by a call centre agent? What is even more frustrating for customers is when they have to phone back for a second time and repeat the whole process again.

\section{PERSONALISATION OR CUSTOMISATION?}

The same kind of dehumanisation applies to written correspondence. More and more companies are using technology to 'personalise' their written correspondence, but in most cases it just touches on the very basics, such as inserting the name and address. This is not personalisation; this is customisation.

Research showed that 89 per cent of companies said they personalise their correspondence. ${ }^{5}$ Of those, 84 per cent said they personalise all the documents sent to their clients, while 50 per cent send more than 10,000 documents per month. It was found that 68 per cent of those who personalise all documents use word-processing tools to manage volume correspondence, indicating that the level of personalisation might be limited just to customisation, that is simply including an addressee's name rather than profiling the content of the document to reflect previous customer contact and his or her specific requests.

This conclusion is further strengthened by the analysis of the methods used for personalisation. It was found that 50 per cent of respondents use fully automated systems, 38 per cent use partially automated systems and 12 per cent personalise communication manually. Real personalisation tools are partially automated, ie standard text (marketing 
information, statements, addresses) is created automatically, but the final touches that make a customer feel that they are treated as an individual and that they are important for the company have to be added manually. Those manual additions would include, for example, personal remarks or references to previous communication.

\section{CUSTOMER DISSATISFACTION}

What this results in is people receiving regular mail from companies with whom they have been a customer, sometimes for years, and the contents are neither relevant to their interests nor their situation. If they take the time to wade laboriously through the jargon, it soon becomes quite clear that these letters have been mailed to thousands of other customers. It is hardly surprising, therefore, that people are dissatisfied. What gives more cause for concern though, is that the overwhelming majority of customers do not express this dissatisfaction, they just move their custom elsewhere. Poor communication can destroy all the effort and investment put into improving customer satisfaction.

These issues are common. Letters sent from a faceless company to a faceless consumer mass are worth little more than the paper on which they are printed. It must be remembered that the personal touch is reciprocally beneficial.

If letters are targeted and more personally relevant, the customer is more likely to be content. This creates a loyalty that necessarily benefits the company. A Gallup survey concluded that 57 per cent of customers are more likely to respond to correspondence that treats them as unique individuals, and only 26 per cent would respond to impersonalised contact.

Personalisation takes into account much more than straightforward customisation. It uses three types of information: first, the factual data stored in databases; secondly, formal data stored in archives or files; and thirdly, the customer information that is not written or stored anywhere but is held in the minds of agents.

\section{THE REAL MEANING OF PERSONALISATION}

Companies are beginning to understand the need to personalise communication, but they are still falling short when it comes to putting theory into practice. When most companies talk about personalisation they mean addressing a letter 'Dear John' rather than 'Dear Customer.' This type of personalisation is typical of batch letters. But there is another type of communication - ad hoc, where personalisation stands for everything. True personalisation might be more expensive to implement, but ad hoc/support communication is a key factor in customer retention and needs a different and more sophisticated type of solution.

Ad hoc/support communication consists of responses to customers' queries as well as communication responding to clients' individual circumstances. This could be anything that is a written reflection of the business process based around customer relations. Ad hoc/support communication is not just limited to letters, but can include e-mails, faxes and short message service (SMS) messages.

Providing that all-important human touch to written communications should really go further than just the mass-produced correspondence (ie direct marketing, bills, statements, invoices, etc.). Attention should also be paid to the front-line communications or 'supporting correspondence', such as ad hoc letters, e-mail responses, reminders and announcements. This is a whole new 
area of communication management that has remained untouched until now, rendering it a prime means of creating a differentiator. It is a reminder of First Direct when it recognised the importance of being able to adopt insurance policies, quickly and conveniently, and the whole industry reassessed its offerings. It will take just one smart company to address support correspondence properly and it will become the catalyst for the rest of the industry.

\section{TECHNOLOGY}

The solution to personalising written correspondence has to lie in technology, because companies need to communicate with such large numbers of customers, and on a one-to-one basis this is totally impractical in terms of time, cost and resources. The more a company wants to personalise, the most costly it can become. So the only sensible way to achieve it is through some form of automation technology. But care needs to be taken, as the technology must be intelligent and sophisticated enough that the human touch is not lost, just balanced. If the automation is too much then the personal touch can be lost and it defeats the original objective.

A good customer content solution will do more than just pull contact details from a database. It will ensure consistency in quality because the sentences, format, grammar and spelling can all be controlled and adjusted to give a personal yet uniform message. It will also maintain a consistent look and feel in order to build and enhance brand awareness. It will integrate corporate and legal stands to protect and improve business operations.

Most companies agree that quality cannot be sacrificed but, because they lack resources, the result is delays in responding to customers. The effect that the quality response would have had on the customer is lost because of the late reply. Customer content solutions can dramatically speed up response times. For example, using the right technology, Columbus Life ${ }^{6}$ achieved time savings of 50 per cent. Kaiser Permanente 7 reduced the number of steps to produce a letter from 14 to two, lowering the overall cost of creating a letter by approximately 54 per cent.

Customer content solutions will also save the company significant sums of money, precisely because they are fast, consistent and accurate - a leading high street bank, for example, cut the cost from $\delta^{9}$ per letter to $\delta^{2}$ per letter. Moreover, there are other savings to be had. Research has shown that over 65 per cent of queries to customer service are simply a case of not understanding the documentation received. Sending out good documentation, in plain English, can significantly reduce customer queries, thereby relieving pressure on telephone staff and decreasing costs.

Technology, on the other hand, has also created its own problems. It has been the root cause in the increase in the volume and forms of written communication - SMS fax, e-mail, etc. - hindering the delivery of good customer service. Some customer content solutions will enable responses in numerous formats depending on what suits the customer best. So, for example, it may be most effective to post a letter to a pensioner but to send a text message to a teenager's mobile phone.

\section{CONCLUSION}

The clever use of communications channels can surpass expectations. A customer may be anxiously waiting for documentation about a property he or she wants to buy. Rather than pacing the 
floor for days on end wondering when or if it will arrive, would the customer not be pleased if his or her solicitor sent a text message to let them know it was in the post and would be with them the next day?

The greatest benefit of customer content solutions, however, is that they can be the basis for a competitive edge. Senior executives know that the competitive battles will involve not only getting better at what their organisations do, but also being different from others. The management of written communications is consistently ignored by businesses, despite the fact that they send out millions of pieces of written correspondence every day. The real cutting edge, though, will come from addressing the front line or 'support' communications - making this consistently well written, accurate, reflecting the corporate brand and still containing that one-to-one feel.

Addressing this properly and consistently is the only way a company will really be ahead of its competitors.

\section{References}

1 Conquest Media (2001), research commissioned by Cincom Systems.

2 Novamétrie (2001).

3 Ibid.

4 Ibid.

5 Gartner (1999).

6 See www.cincom.com/idsolutions

7 Ibid. 